\title{
Duca, um aplicativo civil colaborativo para alavancar a educação
}

\author{
Alan Passos ${ }^{1}$, John Santos ${ }^{1}$, Renan Santos ${ }^{1}$, André Nascimento ${ }^{1}$, Methanias Colaço \\ Júnior $^{1}$, Danilo F. Neves ${ }^{1}$, Aberlado Mota ${ }^{1}$, Eduardo Cortes ${ }^{1}$ \\ ${ }^{1}$ Departamento de Sistema de Informação - Universidade Federal de Sergipe (UFS) - \\ Itabaiana, SE - Brazil \\ \{alanpassossi, renan321san, andreviniciusnascimento\}@gmail.com, \\ \{mjrse, educortes17\} @hotmail.com, johnhed@live.com, \\ abelardomota@yahoo.com.br, danilo.neves@ufs.br
}

\begin{abstract}
Context. The low quality education indices in Brazil demonstrate the damages arising from a sector formed by complex administrative layers and low transparency. Objetive. Through an application whose lovely name is also your mascot, the Duca, facilitate cooperation and social control of the population, as well as direct actions by the control organizations, justice and executive. Method. Beyond to the agile construction of the application, an evaluative case study was conducted with a state public school, in which teachers, students and parents suggested corrections and improvements. Results. The application, as a participatory collaboration tool, promotes the engagement of the school community, changing the life of this community with innovative aspects, among which the possibilities of visualization the oficial menu school lunch and of applications of dynamic surveys. Conclusion. Bringing civil society closer together with governing, the application raise the public governance at the economic, social and academic levels on the perspective of planning more efficient and effective.
\end{abstract}

Resumo. Contexto. Os baixos índices de qualidade de ensino no Brasil demonstram os prejuizos advindos de um setor formado por complexas camadas administrativas e baixa transparência. Objetivo. Por meio de um aplicativo cujo nome carinhoso também é o seu mascote, a Duca, facilitar a cooperação e o controle social da população, bem como direcionar as ações por parte dos órgãos de controle, justiça e poder executivo. Método. Além da construção ágil do aplicativo, um estudo de caso avaliativo foi realizado com uma escola pública estadual, no qual professores, alunos e pais sugeriram correções e melhorias. Resultados. $O$ aplicativo, como ferramenta de colaboração participativa, promove o engajamento da comunidade escolar, mudando a vida desta comunidade com aspectos inovadores, entre os quais se destacaram as possibilidades de visualização do cardápio real da merenda e de aplicações de surveys dinâmicos. Conclusão. Aproximando a sociedade civil com órgãos diretores, a aplicação eleva a governança pública em níveis econômico, social e acadêmico, sob a perspectiva de um planejamento mais eficiente e eficaz. 


\section{Introdução}

Estimativas da Organização para Cooperação e Desenvolvimento Econômico (OCDE) sobre os custos totais gerados pela corrupção global apontam para números em torno de US\$ 2.6 trilhões, o que representa aproximadamente 5\% do PIB mundial [OCDE 2013]. Seus efeitos negativos para a governança pública são notados nos mais diversos setores e afetam diretamente o crescimento econômico, a legitimação de políticas públicas e a eficiência e qualidade dos serviços públicos [Dimant and Tosato 2018].

A educação tem se mostrado um setor propenso à corrupção, formado por complexas camadas administrativas e por baixa transparência. Uma gestão inidônea vê na baixa fiscalização um ambiente propício para esta prática, que vai desde a fraude em licitações e o desvio de verbas, até as próprias ações de ensino e pesquisa, com apadrinhamento na contratação de professores e na distorção de estudos para promoções pessoais [Sweeney et al. 2013].

O resultado da precarização é refletido nos baixos índices de avaliação do PISA (Programme for International Student Assessment). O Brasil figurou abaixo da média em matemática (classificação entre $57^{\circ}$ e $60^{\circ}$ lugares), leitura (classificação entre $54^{\circ}$ e $56^{\circ}$ lugares) e ciências (classificação entre $57^{\circ}$ e $60^{\circ}$ lugares) [OCDE 2012]. Em uma análise de qualidade geral, o Brasil ocupou apenas a $60^{\circ}$ posição entre 76 países avaliados [OCDE 2015].

Neste contexto, a participação popular é tida como um fator preponderante na elaboração de políticas públicas efetivas e na melhoria de serviços públicos. Aliada ao desenvolvimento tecnológico e ao reconhecimento da incapacidade em lidar com problemas complexos sozinha, a nova gestão pública, centrada no cidadão, estabelece como principal linha estratégica atender demandas de transparência e auditoria que promovam o engajamento civil e o controle social [Freitas and Dacorso 2014, Macintosh 2004].

Compreendendo a atuação e os benefícios gerados por esse modelo supracitado, a solução desenvolvida e aqui apresentada arquitetou um ambiente colaborativo, alinhando órgãos fiscalizadores e população. Com foco nos sistemas públicos de ensino, a ferramenta possibilitará o envolvimento da comunidade por meio da comunicação de fatos (positivos ou negativos) acerca dos sistemas públicos de ensino.

\section{Ferramenta}

Carinhosamente chamado de Duca, nome da corujinha mascote que interage com os cidadãos, o aplicativo desenvolvido, inicialmente, sobre a plataforma Android e disponível para download na Google Play ${ }^{1}$, explora a conveniência, a flexibilidade e a mobilidade, oferecendo informações e serviços úteis ao cidadão. Seu desenvolvimento é resultado de uma união inovadora entre o Tribunal de Contas, o Ministério Público e a Universidade Federal de Sergipe, órgãos que vislumbraram a concretização de uma das suas principais linhas estratégicas: a busca pela aproximação com a sociedade civil e pelo incentivo ao cidadão pensante, transformando-o em fiscal do dinheiro público.

\footnotetext{
${ }^{1}$ https://play.google.com/store/apps/details?id=com.ufs.duca.educacaoup
} 
Os benefícios trazidos pela tecnologia abrangem diferentes esferas públicas: o social, colocando o cidadão no processo de tomada de decisão; o econômico, uma vez que um investimento direcionado pode apresentar uma melhor relação custo-benefício; e o acadêmico, uma vez que os dados coletados serão base para geração de suposições e hipóteses experimentadas, testadas e publicadas.

Essencialmente, para o aluno, que, muitas vezes, não possui pleno conhecimento dos seus direitos e fica intimidado em relatar possíveis problemas, a ferramenta garante o apoio pelo sigilo, assegurando que apenas as autoridades responsáveis pela fiscalização tenham acesso a sua identidade, como também pela transparência, disponibilizando dados e informações da unidade para o aluno. Por exemplo, com a disponibilização do cardápio semanal da merenda, o aluno pode comparar e informar uma possível diferença para o que é servido diariamente.

\subsection{Funcionamento da Ferramenta}

$\mathrm{Na}$ aplicação, alunos, professores e todos os envolvidos poderão consultar e avaliar os serviços oferecidos pela unidade escolar. A interação com o governo acontece por meio de manifestações estruturadas, nas quais o cidadão pode emitir uma denúncia, elogio ou sugestão (banco de ideias) sobre a escola.

Para efetivar uma ocorrência, o cliente deve, inicialmente, selecionar uma escola. A Duca lista as unidades de ensino mais próximas do cliente, por meio geolocalização. Após a seleção, o tipo da manifestação é definido, bem como uma transcrição e uma categorização do problema são exigidas. Esta categorização é baseada em uma taxionomia criada com diversos assuntos importantes para Gestão da Educação, tais como alimentação escolar, infraestrutura, transporte e transparência. Ato contínuo e opcionalmente, pesquisas de campo (surveys) sobre estes assuntos podem ter suas questões cadastradas e podem ser aplicadas ao cidadão, gerando uma redução do custo de visitas às escolas. Por fim, fotos podem ser utilizadas para corroborar o registro. Um vídeo com as principais funcionalidades pode ser visto no Facebook ${ }^{2}$ da Duca. Na Figura 1, são apresentadas algumas das telas do aplicativo.

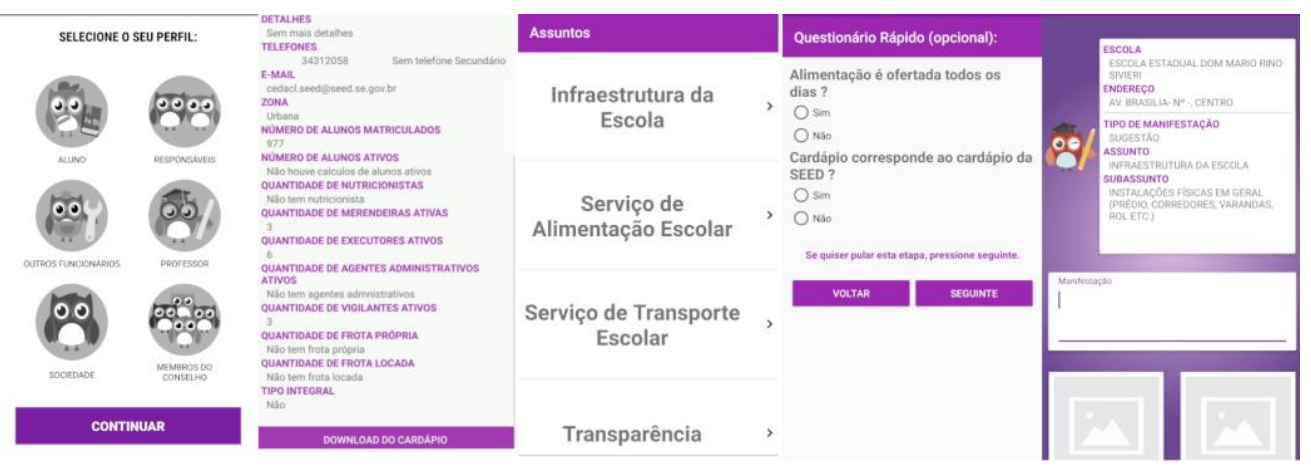

Figura 1. Aplicativo Duca, ambiente colaborativo para alavancar a educação.

Para diminuir o número de denúncias falsas, no momento do cadastro, o aplicativo verifica, por geolocalização, se a foto foi tirada nas cercanias da unidade.

\footnotetext{
${ }^{2}$ https://www.facebook.com/Ducaa/videos/1871034133013625/
} 
Além disto, serão catalogadas as informações pessoais do cidadão e IMEI (Identificação Internacional de Equipamento Móvel).

Em posse dos dados os órgãos fiscalizadores, Tribunal de Contas e Ministérios Públicos Estadual e Federal, poderão direcionar os seus planejamentos estratégicos para os principais problemas. Vale ressaltar que a Duca não pretende denegrir o trabalho das Secretárias de Educação, pelo contrário, o intuito é de apoiar a tomada de decisão da Gestão Pública, por meio de relatórios semanais enviados aos coordenadores e diretores das escolas, os quais permitirão a antecipação das ações pela Gestão.

Um estudo de caso foi realizado em uma escola pública estadual, o qual contou com a participação de 10 alunos, 4 pais e 5 professores. O resultado geral de usabilidade foi satisfatório, contudo, os participantes puderam tecer críticas e encontrar erros, bem como sugerir melhorias e novas funcionalidades.

\section{Conclusão}

Voltado a qualquer cidadão que está envolvido ou deseja contribuir com a educação pública, este aplicativo apresenta uma solução para facilitar a cooperação e o controle social da população, bem como direcionar as ações por parte dos órgãos de controle, justiça e poder executivo.

Este direcionamento inicia-se com a possibilidade de escolha de um perfil específico (Aluno, Responsável, Professor, Sociedade, Outros Funcionários e Membros do Conselho de Educação), o cidadão poderá ajudar a alavancar a educação, tornando os problemas transparentes, sugerindo ideias, elogiando e usando a tecnologia em favor da sociedade.

Como trabalhos futuros, está em desenvolvimento uma plataforma colaborativa que ofereça mecanismos tanto para o planejamento estratégico dos gestores, usando estatísticas dos assuntos importantes para gestão, como também para o suporte ao cidadão, permitindo o acompanhamento e a gestão das intervenções fiscais advindas do Duca. O objetivo será permitir que o órgão de controle possa responder à sociedade, integrando as manifestações com processos oficiais abertos, bem como permitindo que o cidadão veja o que está sendo feito em favor do seu manifesto.

\section{Referências}

Dimant, E. and Tosato, G. (2018). Causes and effects of corruption: what has pastdecade's empirical research taught us? A survey. Journal of Economic Surveys, 32(2):335-356.

Freitas, R.K.V.d. and Dacorso, A.L.R. (2014). Inovação aberta na gestão pública: análise do plano de ação brasileiro para a open government partnership.

Macintosh, A. (2004). Characterizing e-participation in policy-making. In System Sciences, 2004. Proceedings of the 37th Annual Hawaii International Conference on, pages 10-pp. IEEE.

OCDE. (2012). Results From PISA 2012, https://www.oecd.org/brazil/PISA-2012-results-brazil.pdf, Abril-2019.

OCDE. (2013). The Rationale for Fighting Corruption, http://www.oecd.org/cleangovbiz/49693613.pdf, Abril-2019.

OCDE. (2015). Excellence and Equity in Education, http://www.oecd.org/publications/pisa-2015-results-volume-i9789264266490-en.htm, Abril-2019.

Sweeney, G., Despota, K., and Lindner, S. (2013). Transparency international global corruption report: Education. New York: Routlegde. 